\title{
CONF-960204--1
}

UCRL-JC-121374

PREPRINT

\section{Optimization of a CNG Series Hybrid Concept Vehicle}

\author{
Salvador M. Aceves, J. Ray Smith, L. John Perkins, \\ Scott W. Haney, and Daniel L. Flowers
}

This paper was prepared for submittal to 1996 Society of Automotive Engineers International Congress and Exposition Detroit, $M I$

February 26-29, 1996

September 22, 1995

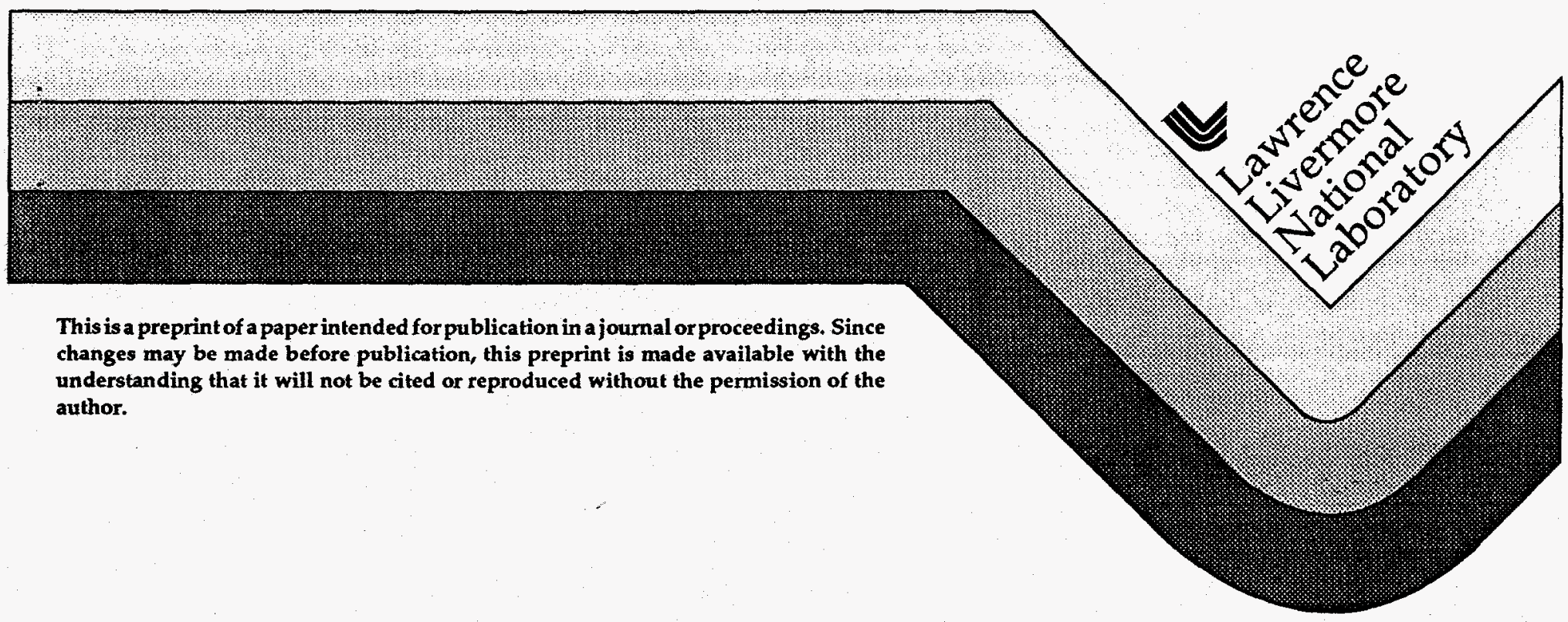




\section{DISCLAIMER}

This document was prepared as an account of work sponsored by an agency of the United States Government. Neither the United States Government nor the University of California nor any of their employees, makes any warranty, express or implied, or assumes any legal liability or responsibility for the accuracy, completeness, or usefulness of any information, apparatus, product, or process disclosed, or represents that its use would not infringe privately owned rights. Reference herein to any specific commercial product, process, or service by trade name, trademark, manufacturer, or otherwise, does not necessarily constitute or imply its endorsement, recommendation, or favoring by the United States Government or the University of California. The views and opinions of authors expressed herein do not necessarily state or reflect those of the United States Government or the University of California, and shall not be used for advertising or product endorsement purposes. 


\section{DISCLAMMER}

Portions of this document may be illegible in electronic image products. Images are produced from the best available original document. 


\title{
OPTIMIZATION OF A CNG SERIES HYBRID CONCEPT VEHICLE
}

\author{
Salvador M. Aceves, J. Ray Smith, L. John Perkins, \\ Scott W. Haney and Daniel L. Flowers \\ Lawrence Livermore National Laboratory, University of California \\ 7000 East Avenue, Livermore, CA 94550
}

\begin{abstract}
Compressed Natural Gas (CNG) has favorable characteristics as a vehicular fuel, in terms of fuel economy as well as emissions. Using CNG as a fuel in a series hybrid vehicle has the potential of resulting in very high fuel economy (between 26 and $30 \mathrm{~km} / \mathrm{liter}, 60$ to $70 \mathrm{mpg}$ ) and very low emissions (substantially lower than Federal Tier II or CARB ULEV). This paper uses a vehicle evaluation code and an optimizer to find a set of vehicle parameters that result in optimum vehicle fuel economy.
\end{abstract}

The vehicle evaluation code used in this analysis estimates vehicle power train performance, including engine efficiency and power, generator efficiency, energy storage device efficiency and state-of-charge, and motor and transmission efficiencies. Eight vehicle parameters are selected as free variables for the optimization. The optimum vehicle must also meet two performance requirements: accelerate to $97 \mathrm{~km} / \mathrm{h}$ in less than $10 \mathrm{~s}$, and climb an infinitely long hill with a $6 \%$ slope at $97 \mathrm{~km} / \mathrm{h}$ with a $272 \mathrm{~kg}(600 \mathrm{lb}$.) payload.

The optimizer used in this work was originally developed in the magnetic fusion energy program, and has been used to optimize complex systems, such as magnetic and inertial fusion devices, neutron sources, and rail guns. The optimizer consists of two parts: an optimization package for minimizing non-linear functions of many variables subject to several non-linear equality and/or inequality constraints and a programmable shell that allows interactive configuration and execution of the optimizer.

The results of the analysis indicate that the CNG series hybrid vehicle has a high efficiency and low emissions. These results emphasize the advantages of CNG as a near-term alternative fuel for vehicles.

\section{INTRODUCTION}

The potential for low-emission Compressed Natural Gas (CNG) engines has been documented in the literature. ${ }^{1,23}$ Two CNG vehicles ${ }^{4,5}$ have been built recently to meet the ultra-low-emission vehicle (ULEV) standards imposed by the California Air Resources 
Board (CARB). Recently, CARB has proposed equivalent-zero-emission vehicle (EZEV) regulations, ${ }^{6}$ which allow low emitting hybrid vehicles to receive full credit as an electric vehicle. These regulations are currently being evaluated for future approval. See Table 1 for current emissions regulations of interest for this analysis. Some of the advantages of CNG as a vehicular fuel are: reduced need for cold-start enrichment, no evaporative emissions, and a high octane number (as high as 130$)^{3}$ which allows knock-free operation at compression ratios of 12:1. Some disadvantages of CNG are the greater weight and volume required for the fuel storage system, and the lack of an extensive fueling infrastructure.

The concept of series hybrid vehicles has been developed recently ${ }^{7,9}$ with the purpose of obtaining a very high fuel economy simultaneously with very low emissions. Series hybrid vehicles operate with an engine in an on-off mode", with no mechanical link between the engine and the wheels. An electric motor provides the tractive power. When the engine is running, it drives a generator that supplies electricity to both the electric motor and an energy storage system. Flywheels, ultracapacitors and advanced batteries are possible storage systems. When the storage system is fully charged, the engine is turned off, and the storage system provides all the energy required for drivetrain and accessories.

Series hybrid vehicles have high fuel economy because the engine is both sized closer to the car's average power consumption and operated at a high efficiency condition without ever idling. Spark ignition engines can be run unthrottled thus avoiding pumping losses. Engines in series hybrids operate most of the time at a low power, high efficiency condition, at constant speed and load. When additional power is required during long hill climbs, the engine can be operated at a high power level, trading off some fuel economy for the capability of climbing long hills at acceptable speed.

Series hybrid vehicles have low emissions because engine operation is not linked to vehicle driving conditions; therefore, high emissions are avoided during hard accelerations. The storage system can also be monitored to predict when the engine will need to be started. This enables preheating the catalytic converter and engine oil, if necessary, to reduce emissions and friction during the startup.

\footnotetext{
- On-off mode operation in a conventional drivetrain has recently been brought to the European market by Volkswagen in its Ecomatic automobile [10].
} 
This paper presents the optimization of two CNG series hybrid concept vehicles, one operating with a stoichiometric engine and the other with a lean-burn (fuel-air equivalence ratio $\phi=0.6$ ) engine. The vehicles are optimized for maximum fuel economy. The purpose of this analysis is to compare these two vehicles in terms of fuel economy and emissions. The results can then be used for evaluating the application of these concept vehicles for approaching the $34 \mathrm{~km} / 1(80 \mathrm{mpg})$ fuel economy goal of the Partnership for a New Generation of Vehicles (PNGV); and for qualifying as ULEV or EZEV. The paper also shows the use of a sophisticated optimizer to find optimum operating conditions that would otherwise be hard to find. Some of the performance-fuel economy trade offs that exist in series hybrid vehicle design are also discussed and illustrated. This paper is also a part of a project which focuses on developing high-efficiency engines for series hybrid vehicles. While many of the assumptions used in the modeling are subjected to experimental verification, it is considered that the modeling effort is detailed enough that it can provide useful guidance in the ongoing experimental work. Although the main thrust of this project is optimized engines for hydrogen, the approach and methodology are directly applicable to CNG. The hydrogen series hybrid project is described in more detail in. ${ }^{11,12}$

The optimization of the CNG concept vehicles is done by linking an optimizer to an existing hybrid vehicle simulation code. The following sections describe the most important aspects of the optimizer and the vehicle evaluation code.

\section{THE OPTIMIZER}

The SUPERCODE ${ }^{13}$ is used for the vehicle optimization. The SUPERCODE was developed originally for the U.S. Magnetic Fusion Program for optimizing tokamak reactors and experimental designs. ${ }^{14}$ It has subsequently been used to optimize inertial fusion devices and rail-guns, in addition to the present application. The SUPERCODE consists of a programmable shell that is tightly coupled to a constrained optimization package. It is a portable system, running on a variety of workstations, personal computers, and supercomputers.

The SUPERCODE uses the VMCON package, ${ }^{15}$ an implementation of a variable metric method developed by M.J.D. Powell to solve constrained non-linear optimization problems. That is, it attempts to minimize a non-linear figure of merit $f(x)$ subject to $M$ non-linear inequality constraints $g_{i}(x) \geq 0$ and $N$ non-linear equality constraints $h_{j}(x)=0$ over $k$ bounded variables $\mathrm{l}_{\mathbf{k}} \leq \mathrm{x}_{\mathbf{k}} \leq \mathrm{u}_{\mathrm{k}}$. 
The SUPERCODE is controlled using a powerful programmable shell that takes input using a variant of the $\mathrm{C}++$ language. This input can be from the terminal or from files, allowing interactive or batch operation of the code. The user can define real, integer, complex, array, and string variables. In addition, the language supports control statements, loops and functions. Finally, the shell can exploit the multi-processing capabilities of UNIX to run external programs, such as the vehicle simulation code, to compute constraint and figure of merit values. It is even possible to use the parallel virtual machine (PVM) system $^{16}$ to simultaneously run multiple copies of the external program in parallel on a number of workstations thereby dramatically reducing execution time.

This programmable shell offers tremendous flexibility for the user to specify an optimization problem. Once the optimization is completed, the user can interrogate the shell for variable and figure-of-merit values. Also, variables can be fixed or new bounds or constraints applied to investigate "what-if" scenarios. Finally, loops can be written to perform parameter scans.

\section{THE VEHICLE EVALUATION CODE}

The hybrid vehicle evaluation code (HVEC) ${ }^{17}$ can be applied to many of the vehicles currently being considered for high fuel economy and low emissions. It has been used in the past for analyzing hydrogen hybrid vehicles. ${ }^{11}$ HVEC calculates vehicle fuel economy, maximum effort acceleration and continuous hill climbing performance. The model is based on detailed engineering models of the different vehicle components, including fuel converter (engine-generator or fuel cell), battery, flywheel, ultracapacitor, and tractive drive motor.

The evaluation code includes an engine-generator model, which uses first principles and correlations to predict piston engine efficiency and power output. Generator efficiency is calculated from a manufacturer's performance map, which gives generator efficiency as a function of generator speed and torque. The engine model is a lumped (zero-dimensional), time-dependent model which solves the basic differential equations for the compression and power strokes. An empirical expression is specified for the shape of the heat release curve. The burn duration can be specified for any given engine. The engine model adjusts the spark ignition timing to the value that yields the maximum engine efficiency.

Engine heat transfer and friction reduction have been recognized as very important for achieving the high efficiencies required for PNGV mileage goals. Engine heat transfer can 
be reduced by using a combustion chamber with minimum surface area-to-volume ratio and low turbulence. These requirements indicate that a long stroke engine with a flat piston and cylinder head has the potential for high efficiency. ${ }^{12}$ The long stroke minimizes the surface to volume ratio, while the lack of squish contributes to low surface to volume as well as low turbulence. The engine model uses Woschni's correlation ${ }^{18}$ to estimate engine heat transfer. This correlation is given as:

$$
h=3.26 B^{-0.2} P^{0.8} T^{-0.55} w^{0.8}
$$

where $\mathrm{h}$ is the heat transfer coefficient in $\mathrm{W} / \mathrm{m}^{2} \mathrm{~K}, \mathrm{~B}$ is the cylinder bore in $\mathrm{m}, \mathrm{P}$ is the pressure in $\mathrm{kPa}, \mathrm{T}$ is the mass-averaged temperature in $\mathrm{K}$, and $\mathrm{w}$ is a measure of the gas velocity inside the cylinder, given as:

$$
w=C_{1} S_{p}+C_{2} V_{d} T_{r}\left(p-p_{m}\right) / p_{r} V_{r}
$$

Where $C_{1}=2.28$ during the compression and expansion periods; $S_{p}$ is the mean piston speed; $C_{2}=0.00324 ; V_{d}$ is the displaced volume; $T_{r}, p_{r}$ and $V_{r}$ are temperature, pressure and volume at a reference state; and $\mathrm{p}-\mathrm{p}_{\mathrm{m}}$ is the difference between the cylinder pressure and the motored pressure. Values for all the variables are a function of time, and are calculated for each crank angle degree of engine rotation.

The engine model incorporating Woschni's correlation was observed to predict accurately the efficiency of stoichiometric engines. For lean-burn engines, however, Woschni's correlation overpredicts heat transfer losses. It was found that using $1 / 2$ of the original constant $\mathbf{C}_{1}$ for lean burn engines yields good results, and therefore this value is used. The results obtained from the engine model with this reduced constant have been compared with experimental data from the literature in a previous paper, ${ }^{12}$ and have been found to match the data to a good approximation.

The engine model uses the Barness-Moss friction correlation. ${ }^{19}$ This is given as:

$$
\text { fmep (bar) }=0.97+0.15 \mathrm{~N} / 1000+0.05 \mathrm{~N}^{2} / 1000^{2}
$$

where fmep is friction mean effective pressure, and $\mathrm{N}$ is engine speed in rpm. Comparing this equation with a more detailed and recent correlation by Patton et al. ${ }^{20}$ (Fig. 1), it was observed that the more detailed correlation predicts about $65 \%$ of the friction given by Eq. (3). Therefore, $65 \%$ of the friction losses given by the Barness-Moss' correlation are used for the model. The more detailed model ${ }^{20}$ was not used to keep the engine model 
simple. The fact that the more recent correlation predicts lower friction is attributed to improvements in engine technology. It is believed that engines with even lower friction can be built, especially if the engines operate at limited speed, as the ones used for series hybrid vehicles, even though it has been shown that long stroke engines (which are desirable for reducing heat transfer losses) tend to have increased friction losses. ${ }^{20}$

\section{THE VEHICLES}

The two vehicles considered in this paper are piston engine-generator series hybrid vehicles using a flywheel for energy storage. One of the vehicles uses a stoichiometric engine and the other a lean burn $(\phi=0.6)$ engine. These vehicles are conceived as full-purpose, fullrange $(610 \mathrm{~km} ; 380$ miles) vehicles that can perform as well as current vehicles while at the same time having a very high mileage and very low emissions. Some of the vehicle parameters kept constant during the optimization process are listed in Table 2. The $1000 \mathrm{~W}$ accessory load is considered a reasonable average for year-round driving conditions. It is recognized that accessory loads have a great effect on fuel economy for high efficiency vehicles, including series hybrid vehicles. It has been determined as a part of this analysis that reducing the accessory load by $1.7 \mathrm{~W}$ has the same effect on fuel economy as reducing the vehicle weight by $1 \mathrm{~kg}$.

Both vehicles use a preheated catalytic converter to reduce cold start emissions. The energy required to preheat the catalytic converter $\left(0.05 \mathrm{kWh}^{21}\right)$ is deducted from the flywheel every time the engine is cycled on. This is a conservative assumption, since the catalytic converter can probably be kept hot between cycles, at least during long trips.

It is expected that minimum emissions will occur for either stoichiometric engines or for engines operating at the minimum possible $\phi$. At stoichiometric conditions, three-way catalysts have very high efficiencies, especially under the constant speed and load and preheated catalyst conditions existing in series hybrids. At lean conditions, emissions of $\mathrm{NO}_{\mathrm{x}}$ drop as the equivalence ratio is decreased. Lean-burn catalysts are being developed, and operate best at high ratios of hydrocarbon to $\mathrm{NO}_{\mathrm{x}}{ }^{22}$ which are likely to be found for the minimum possible equivalence ratios. The value of $\phi=0.6$ is selected as the minimum equivalence ratio that has been demonstrated without excessive cyclic variations. ${ }^{23}$ Lower equivalence ratios can be used if enhanced ignition systems are used. These would probably result in slightly higher fuel economy and lower emissions. Both engines use homogeneous charge to minimize $\mathrm{NO}_{\mathrm{x}}$ production. ${ }^{24}$ 
The engines for the series hybrid vehicles analyzed in this paper operate most of the time at low power, high efficiency, constant speed and load conditions to obtain a high fuel economy. However, the engine power can be increased to a high level to meet the requirement for long hills. High power conditions for the stoichiometric engine are obtained by increasing the engine speed. Maximum engine speed is limited by either the maximum power envelope for the selected generator, or by the requirement that the mean piston speed should not exceed $15 \mathrm{~m} / \mathrm{s}^{25}$ Figure 2 shows the stroke, bore and engine speed for $15 \mathrm{~m} / \mathrm{s}$ mean piston speed, as a function of engine displacement, for the 2-cylinder, 0.833 bore to stroke ratio engine assumed for this analysis. For the lean burn engine, high power is achieved by enriching the mixture to stoichiometric operation, and then by increasing the engine speed until reaching the maximum power allowed by the generator, or the maximum mean piston speed. Since the lean burn engine operates part of the time at stoichiometric conditions, it requires a three-way catalyst as well as a lean burn catalyst.

A generator with the characteristics of a commercially available permanent magnet motor ${ }^{26}$ is selected for this application. The generator performance map is shown in Fig. 3. It is assumed that a generator can be built for any maximum torque and speed, so that the performance map can be scaled as required. The engine and the generator are directly coupled, and therefore operate at the same shaft speed.

Both engines are assumed to be naturally aspirated to reduce system complexity and cost. Volumetric efficiency (defined as including air and fuel mass) is assumed equal to $100 \%$, because single point operation allows tuning both intake and exhaust.

Vehicle weights are estimated by assuming that it is possible to build a gasoline series hybrid vehicle with a $1064 \mathrm{~kg}$ empty weight (1200 kg test weight). The weight of the vehicles is then calculated by replacing components from the gasoline hybrid as required, and calculating the differences in weight between the replaced components. It is also assumed that the chassis weight has to be increased by $0.3 \mathrm{~kg}$ for each $\mathrm{kg}$ of power train weight increase, due to the need for providing the required structural support.

The vehicles are optimized for maximum fuel economy, with the requirements that they accelerate from $0-97 \mathrm{~km} / \mathrm{h}(60 \mathrm{mph})$ in $10 \mathrm{~s}$ or less, and climb a $6 \%$ continuous slope at $97 \mathrm{~km} / \mathrm{h}(60 \mathrm{mph})$. Payload for the hill climb is increased to $272 \mathrm{~kg}(600 \mathrm{lb}$.). The following free variables are used in the optimization: engine displacement and engine speed; storage system energy and power capacities; maximum motor torque, transmission ratio; 
and ratio of generator torque to optimum generator torque, and ratio of generator speed to optimum generator speed at point of operation for the low power conditions. The last two variables are explained in detail later in the paper.

The vehicle evaluation code does not include a detailed model for emissions. Instead, emissions for the stoichiometric engine are estimated by multiplying the certification values

for the CNG Chrysler Minivan ${ }^{27,28}$ by the fuel economy ratio between the minivan and the series hybrid vehicle. This calculation assumes that both engines have the same emissions per unit of energy consumption. This is clearly a conservative assumption, since an engine operating at fixed conditions, with a preheated catalyst should have lower emissions than an engine operating over variable conditions with no catalyst preheating.

Emissions for the lean burn engine are estimated from recent experimental data. ${ }^{23,29}$ It is assumed that $10 \%$ of the hydrocarbon emissions are non-methane. Lean-burn emissions are reported as engine-out emissions, since lean burn catalytic converters are still in the development stage.

\section{RESULTS}

Table 3 lists the main results of the optimization. The stoichiometric engine is smaller than the lean burn engine, due to the higher power per unit of displacement available for stoichiometric engines. Flywheel energy storage capacities are relatively big $(\sim 1.2 \mathrm{kWh})$, because a flywheel with a big energy storage capacity results in longer on- and off-cycles for the engine (the engine has to operate longer to charge a big flywheel, and, once charged, the big flywheel takes longer to discharge). The high energy penalty that has to be paid for heating the catalytic converter every time the engine is turned on makes it desirable to have long engine on- and off-cycles. The other independent variables are very similar for the two vehicles, except for the ratios of generator speed to optimum speed and torque to optimum torque. These ratios indicate the point in the performance map at which the generator operates in the low power and high efficiency conditions. These points are shown in the generator performance maps (Figs. 3 and 4), along with the location of the points for high power operation. Figure 3 shows that the stoichiometric engine operates very near the optimum point for the generator ( 0.97 speed ratio and 1.01 torque ratio), with a very high efficiency (95.3\%). For the high power operation, the stoichiometric engine speed is increased to $4570 \mathrm{rpm}$. Figure 4 and Table 3 indicate that the lean burn engine operates at a ratio of speed to optimum speed (0.93) and torque to optimum torque (0.92) that are lower than the optimum, reducing the generator efficiency to $93.7 \%$. High power 
for the lean engine is obtained first by enriching to stoichiometric and then by increasing the engine speed until reaching the maximum power envelope for the generator.

While it may seem that generator operation near the optimum gives an advantage to the stoichiometric vehicle, this is not the case. The lean burn engine has a greater capacity to increase the power from the low power conditions to the high power conditions (since the equivalence ratio can be increased in addition to the engine speed). The lean vehicle system can take advantage of this added flexibility by reducing the power for the low power condition (17.4 kW instead of $23.1 \mathrm{~kW}$ for the stoichiometric engine), while keeping the same high power capability. This lower power is better matched to the average driving conditions, which results in a better vehicle system efficiency. Average engine on-off cycles are longer for the lean vehicle (Table 3), resulting in fewer engine starts, and therefore a lower penalty for preheating the catalytic converter. In addition to this, the generator efficiency at the high power conditions is higher for the lean burn vehicle. This allows the use of a smaller generator for the same power output, reducing the weight.

The trade off between generator efficiency and power output is very sensitive to the type of generator selected for the application. The use of different types of generators was not explored in this work. There is also the possibility of fabricating a generator with characteristics especially suited to optimize vehicle fuel economy. This would result in an increased fuel economy.

The high fuel economy of series hybrid vehicles reduces the problems associated with onboard storage of CNG. The weight and volume of the storage tanks are given in Table 3 for a $20 \mathrm{MPa}(3000 \mathrm{psi})$ kevlar vessel with aluminum lining. ${ }^{30}$ The weight of the tanks is approximately the same as required for a $10.6 \mathrm{~km} / 1(25 \mathrm{mpg})$ gasoline vehicle to achieve the $610 \mathrm{~km}$ (380 mile) range.

The test weight of the two vehicles is almost identical. The lean burn car has a heavier engine, but this is compensated by a lighter generator and fuel tank (for equal $610 \mathrm{~km}$ range and acceleration), so that the lean burn car is about $10 \mathrm{~kg}$ lighter.

Combined cycle fuel economies are $27.7 \mathrm{~km} / 1(65.2 \mathrm{mpg})$ and $29.0 \mathrm{~km} /(68.1 \mathrm{mpg})$ respectively for the stoichiometric and the lean burn vehicles. The higher engine and system efficiencies for the lean burn car are responsible for this $4.4 \%$ increase in fuel economy. 
The stoichiometric engine has emissions that are a small fraction of ULEV limits and meet the EZEV standards for $\mathrm{NO}_{\mathbf{x}}$. As discussed earlier, these values are probably upper bounds, since they are calculated from data for an engine that operates with varying loads without catalytic converter preheating. It is possible that the EZEV NMHC limit can also be reached, which would allow CNG series hybrid vehicles to receive full ZEV credit. This is subject to future experimental verification.

The lean-burn engine meets ULEV emissions for $\mathrm{CO}$ without a catalytic converter, but not for NMHC or $\mathrm{NO}_{\mathrm{x}}$. Meeting the ULEV limits for NMHC should be possible with a preheated catalyst. Obtaining ULEV NO $\mathrm{x}_{\mathrm{x}}$ emissions requires a lean-burn catalyst with at least $72 \%$ conversion efficiency. Reaching EZEV NO ${ }_{x}$ emission levels requires a lean-burn catalyst efficiency in excess of $97 \%$, which appears to be difficult to achieve at the present time. ${ }^{31}$

The high fuel economy obtained by the series hybrid CNG vehicles has the additional advantage of reducing fuel cycle emissions. Fuel cycle emissions are the emissions resulting from processing and transporting the fuel to the user. Fuel cycle emissions have been determined for some common fuels, ${ }^{28}$ and it has been shown that they are not negligible compared to direct vehicle emissions. For some fuels and pollutants, fuel cycle emissions represent the greatest component of the overall (fuel cycle plus direct) vehicle emissions. Series hybrid vehicles have between 2 and 3 times the fuel economy of conventional cars, and fuel cycle emissions expressed in $\mathrm{g} / \mathrm{km}$ are reduced by this same factor. A calculation based on the results given in ${ }^{28}$ indicates that CNG series hybrid vehicles have slightly lower NMHC and CO fuel cycle emissions than electric cars; while $\mathrm{NO}_{\mathrm{x}}$ fuel cycle emissions for the series hybrid represent a small fraction of those obtained for electric cars.

Figures 5-8 are shown to illustrate some of the trade offs existing in the optimization process. Figures 5 and 7 are for the stoichiometric car and Figs. 6 and 8 are for the leanburn car. Figures 5 and 6 show contour plots of fuel economy as a function of engine speed and displacement; and Figs. 7 and 8 show contour plots of continuous hill climbing slope at $97 \mathrm{~km} / \mathrm{h}$ as a function of engine speed and displacement. All the figures also show a point representing the optimum operating conditions. All the points in these graphs meet the minimum acceleration requirement of $10 \mathrm{~s}$ for $0-97 \mathrm{~km} / \mathrm{h}$. 
Figures 5 and 6 show a region in the lower left corner where the engine does not provide enough power to satisfy the requirements of the driving cycles. This region is bigger for the lean-burn engine, due to the lower power available. Highest fuel economies are obtained for medium to high speed engines that have just enough power to meet the average power required by the driving cycles, due to the optimum match between engine-generator power and driving cycle requirements. For low engine speeds, engine efficiencies drop due to increased heat transfer losses. This effect is apparent in the figures, because reduced engine efficiencies cause the constant fuel economy lines to turn to the left as engine speeds are decreased.

Increasing engine displacement and speed results in a decreased fuel economy. However, engine power can be increased substantially without resulting in a big loss in fuel economy. Figures 5 and 7 show that it is possible to design a $25.5 \mathrm{~km} / 1(60 \mathrm{mpg})$ vehicle with enough power (62 kW) to climb a $10 \%$ continuous slope at $97 \mathrm{~km} / \mathrm{h}$.

Figures 7 and 8 show lines of continuous hill climbing performance as a function of engine displacement and engine speed at the low power condition. Engine speed at the low power condition is used in these figures to make the points correspond identically with the points in Figs. 5 and 6. This makes it possible to read directly from the figures the fuel economy and hill climbing performance for any engine design. However, it is important to notice that the engine does not operate at the low power speed for the extended length hill climb. Instead, it operates at a higher speed, limited by either the generator power capacity, or the maximum mean piston speed of $15 \mathrm{~m} / \mathrm{s}$. For example, the optimum stoichiometric engine has a $2400 \mathrm{rpm}$ speed at the low power conditions, as indicated by a point in Figs. 5 and 7 , but for the hill climb the engine speed is increased to $4570 \mathrm{rpm}$ (Table 3 ).

Figures 7 and 8 also show a line that separates the region of generator-limited maximum power from the region of mean-piston-speed-limited maximum power. The separation between the two regions is clear. For the region of generator-limited maximum power, located in the lower part of the figure, increasing the engine speed allows the designer to reduce the engine size for any continuous slope climbing requirement. When the limit in mean piston speed is reached, no further increases in maximum power can be obtained by increasing the engine speed at low power conditions. Therefore, the lines show a sudden change in slope, and become nearly vertical, as no further reduction in engine displacement can be obtained by increasing the engine speed for any slope climbing requirement. 
The optimum engine operating condition for the stoichiometric vehicle is located at the intersection of the $6 \%$ climbing slope restriction and the maximum mean piston speed restriction. This is because there is no advantage in increasing engine speed to reduce engine size beyond this point. Lean burn engines obtain some of the power increase from low power to high power by enriching to stoichiometric, and they do not require very high speed operation to obtain the high power. Therefore, the maximum piston speed limit for lean engines is reached only at very high speeds. These speeds are too high to have an effect in determining the optimum, which instead is determined by a trade-off between heat transfer (which decreases with engine speed), engine friction (which increases with engine speed), and power train losses (which increase with engine speed). Fuel economy around the optimum is fairly constant, so that the engine design can be changed to accommodate other design constraints without suffering excessive losses.

\section{CONCLUSIONS}

A stoichiometric and a lean burn CNG series hybrid vehicles have been optimized for high fuel economy. The optimization is done by incorporating a vehicle simulation code into a general purpose optimizer. Eight vehicle parameters are used as independent variables, and the vehicles are required to meet minimum hill climb and acceleration requirements. The following are the main conclusions obtained from the analysis.

1. Both vehicles have high fuel economies, with the lean burn engine having $4 \%$ higher fuel economy than the stoichiometric engine. Vehicle emissions for the stoichiometric vehicle are conservatively estimated to be of the order of $10 \%$ of CARB ULEV emissions, and this vehicle may be able to meet CARB EZEV emissions. The lean burn vehicle is expected to have higher emissions than the stoichiometric engine, but should be able to achieve Tier II and CARB ULEV emissions. The exact emission levels for the lean burn engines depend on the conversion efficiencies achievable with lean burn catalysts. In addition to the low direct emissions that can be obtained with these vehicles, the high vehicle fuel economy results in 2 to 3 times lower fuel cycle emissions than those obtained from a conventional car.

2. The use of a sophisticated optimizer for this very complex problem with eight independent variables and two inequality constraints yields optimum operating conditions that would otherwise be difficult to find. Although it is recognized that many of the assumptions used in the modeling are subjected to experimental verification, it is expected 
that the results of this analysis will provide useful guidance in the ongoing experimental work on optimized engine development.

3. The analysis presents the major performance-fuel economy trade offs to be encountered in series hybrid vehicle development. The trade offs illustrated in this paper include generator power and operating point, as well as engine displacement and speed. The effect of these variables on performance and fuel economy is discussed in detail.

\section{ACKNOWLEDGMENTS}

This work performed under the auspices of the U.S. Department of Energy by the Lawrence Livermore National Laboratory under Contract No. W-7405-ENG-48. 


\section{REFERENCES}

1) Siewert, R. M., Mitchell, P. J., and Mulawa, P. A., 1993, "Environmental Potential of Natural Gas Fuel for Light-Duty Vehicles: An Engine-Dynamometer Study of Exhaust-Emission-Control Strategies and Fuel Consumption," SAE Paper 932744.

2) Varde, K. S., Cherng, J. C., Bailey, C. J., and Majewski, W. A., 1992, "Emissions and their Control in Natural Gas Fueled Engines," SAE Paper 922250.

3) Weaver, C .S., 1989, "Natural Gas Vehicles - A Review of the State-of-the-Art," SAE Paper 892133.

4) Cogan, R. J., Editor, 1993, "Chrysler Expands NGV Lineup," Green Car Journal, Vol 2, p. 38.

5) Cogan, R. J., Editor, 1995, "Ford Crown Victoria Dedicated NGV Sedan Nears Market Introduction," Green Car Journal, Vol 4, No. 7, p. 73.

6) California Air Resources Board, Mobile Sources Division, 1995, "Proposed Ammendments to the Low-Emission Vehicle Regulations to Add an Equivalent ZeroEmission Vehicle (EZEV) Standard and Allow Zero-Emission Vehicle Credit for Hybrid Electric Vehicles," Preliminary Draft Staff Report, CARB, El Monte, CA, July 14.

7) Burke, A. F., 1992, "Hybrid/Electric Vehicle Design Options and Evaluations," SAE paper 920447.

8) Smith, J. R., 1993, "The Hydrogen Hybrid Option," Proceedings of the Workshop on Advanced Components for Electric and Hybrid Electric Vehicles, Gaithersburg, MD, NIST special publication 860.

9) Ross, M., and W. Wu, 1995, "Fuel Economy Analysis for a Hybrid Concept Car Based on a Buffered Fuel-Engine Operating at a Optimal Point," SAE paper 950958.

10) Volkswagen, 1994, "Green VW," Vehicle News, Number 211, November/December, pp. 196-199.

11) Smith, J. R., Aceves, S. M., and Van Blarigan, P., 1995, "Series Hybrid Vehicles and Optimized Hydrogen Engine Design," SAE Paper 951955.

12) Smith, J. R., Aceves, S. M., Johnson, N. L., and Amsden, A. A., 1995, "Progress Toward an Optimized Hydrogen Series Hybrid Engine," Proceedings of the 1995 Fall Technical Conference, Internal Combustion Engine Division, ASME, Milwaukee, WI.

13) Haney, S. W., Barr, W. L., Crotinger, J. A., Perkins, L. J., Solomon, C. J., Chaniotakis, E. A., Freidberg, J. P., Wei, J., Galambos, J. D., and Mandrekas, J., 1992, "A SUPERCODE for Systems Analysis of Tokamak Experiments and Reactors," Fusion Technology, Vol. 21, p. 1749. 
14) Galambos, J. D., Perkins, L. J., Haney, S. W., and Mandrekas, J., 1995, "Commercial Tokamak Reactor Potential with Advanced Tokamak Operation," Nuclear Fusion, Vol. 35, p. 551.

15) Crane, R. L., Hillstrom, K. E., and Minkoff, M., 1979, "VMCON, implementation of a variable metric method for constrained optimization developed by M.J.D. Powell," computer program.

16) Beguelin, A., Dongarra, J., Geist, A., Manchek, R., and Sunderam, V., 1991, "Users Guide to PVM: Parallel Virtual Machine," ORNL/TM-11826, Mathematical Sciences Section, Oak Ridge National Laboratory.

17) Aceves, S. M., and J. R. Smith, 1995, "A Hybrid Vehicle Evaluation Code and Its Application to Vehicle Design," SAE paper 950491.

18) Woschni, G., 1967, "Universally Applicable Equation for the Instantaneous Heat Transfer Coefficient in the Internal Combustion Engine," SAE Paper 670931.

19) Barnes-Moss, H. W., 1975, "A Designer's Viewpoint," Passenger Car Engines Conference Proceedings, Institution of Mechanical Engineers, London, pp. 133-147.

20) Patton, K. J., Nitschke, R. G., and Heywood, J. B., 1989, "Development and Evaluation of a Friction Model for Spark-Ignition Engines," SAE Paper 890836.

21) Hamai, K., Mitsumoto, H., Iwakiri, Y., Ishihara, K., Ishii, M., 1992, "Effects of Clean Fuels (Reformulated Gasolines, M85 and CNG) on Automotive Emissions," SAE Paper 922380.

22) Kharas, K. C. C., Silver, R. G., Robota, H. J., and Skowror, J.F., 1993, "The Catalytic Implications of Lean Burn Engines: An Analysis of the Factors Required to Meet Overall Emissions Requirements," SAE Paper 932762.

23) Olsson K., and Johansson, B., 1995, "Combustion Chambers for National Gas SI Engines Part 2: Combustion and Emissions," SAE paper 950517.

24) Homan, H. S., 1978, "An Experimental Study of Reciprocating Internal Combustion Engines Operated on Hydrogen," $\mathrm{PhD}$ thesis, Cornell University.

25) Heywood, J. B., 1988, Internal Combustion Engine Fundamentals, McGraw-Hill, New York.

26) Eriksson, S., 1995, "Drive Systems with Permanent Magnet Synchronous Motors," Automotive Engineering, February, pp. 75-81.

27) Geiss, R., Burkmyre, W., and Lanigan, J., 1992, "Technical Highlights of the Dodge Compressed Natural Gas Ram Van/Wagon," SAE Paper 921551.

28) Darrow, K. G., 1994, "Light-Duty Vehicle Full Fuel Cycle Emissions Analysis," Report Prepared for Gas Research Institute, Contract No. 5093-294-2573. 
29) Clarke, D. P., Such, C. H., Overington, M. T., and Das, P. K., 1992, "A Lean Burn Turbocharged Natural Gas Engine for the U.S. Medium Duty Automotive Market," SAE Paper 921552.

30) DeLuchi, M. A., Johnston, R. A., and Sperling, D., 1988, "Methanol vs. Natural Gas Vehicles: A Comparison of Resource Supply, Performance, Emissions, Fuel Storage, Safety, Costs, and Transitions," SAE Paper 881656.

31) Hair, L., 1995, Personal Communication, Lawrence Livermore National Laboratory, Livermore, CA. 
Table 1. Emission limits in $\mathrm{g} / \mathrm{km}$ ( $\mathrm{g} /$ mile in parentheses) for non-methane hydrocarbons (NMHC), carbon monoxide ( $\mathrm{CO})$, and nitrogen oxides $\left(\mathrm{NO}_{\mathrm{x}}\right)$, allowed by three regulations of interest for this analysis.

$\begin{array}{llll} & \text { NMHC } & \mathrm{CO} & \mathrm{NO}_{\mathrm{x}} \\ \text { Federal Tier II } & 0.078(0.125) & 1.05(1.7) & 0.124(0.2) \\ \text { CARB ULEV } & 0.025(0.040) & 1.05(1.7) & 0.124(0.2) \\ \text { CARB EZEV } & 0.0025(0.004) & * * & 0.0124(0.02)\end{array}$

* Preliminary proposed values. Approval pending.

** No value given in preliminary proposal.

Table 2. Parameters common to the two vehicles being analyzed.

Frontal area, $\mathrm{m}^{2}$

2.04

Aerodynamic drag coefficient

0.24

Coefficient of rolling friction

0.007

Transmission efficiency (single speed)

0.95

Accessory load, W

1000

Energy required for preheating catalytic converter, $\mathrm{kWh} \quad 0.05$

Engine compression ratio

12:1

Ratio of bore to stroke

0.833

Number of engine cylinders

2

Available energy recovered by regenerative braking, $\%$

80

Vehicle range, $\mathrm{km}$ (mi)

$610(380)$ 
Table 3. Main characteristics of the optimum stoichiometric and lean-burn engine series hybrid vehicles.

Independent variables stoichiometric lean burn

Displacement, liters $1.04 \quad 1.23$

RPM at low power condition

$2400 \quad 2400$

Flywheel energy storage, $\mathrm{kWh}$

Flywheel power capacity, $\mathrm{kW}$

$1.20 \quad 1.16$

Motor maximum steady torque

80

97.5

80

Transmission reduction ratio (motor $\mathrm{rpm} /(\mathrm{m} / \mathrm{s})$ )

297

97.4

Generator operating point, $\mathrm{rpm} / \mathrm{rpm}_{\mathrm{opt}}$

0.97

300

Generator operating point, Torque/Torque ${ }_{\text {opt }}$

1.01

0.93

0.92

Engine-generator characteristics at low power

Engine-generator power, $\mathrm{kW}$

Engine brake thermal efficiency, \%

Generator efficiency, \%

Engine-generator characteristics at high power

Engine-generator power, $\mathrm{kW}$

Engine brake thermal efficiency, \%

Generator efficiency, \%

Engine speed, RPM

Maximum RPM allowable

Vehicle characteristics

Power train weight, $\mathrm{kg}$

Fuel tank weight including fuel and mounting, $\mathrm{kg}$

Fuel tank total volume, liters (gal)

Total vehicle test weight, $\mathrm{kg}$

Engine average on-time, combined cycle, $s$

Engine average off-time, combined cycle, $s$

Fuel economy, urban cycle, $\mathrm{km} / \mathrm{l}$ (mpg)

Fuel economy, highway cycle, $\mathrm{km} / \mathrm{l}$ (mpg)

Fuel economy, combined cycle, $\mathrm{km} / \mathrm{l}$ (mpg)

CO emissions, $\mathrm{g} / \mathrm{km}$ ( $\mathrm{g} / \mathrm{mile}$ )

NMHC emissions, $\mathrm{g} / \mathrm{km}$ ( $\mathrm{g} / \mathrm{mile})$

$\mathrm{NO}_{\mathrm{x}}$ emissions, $\mathrm{g} / \mathrm{km}$ ( $\mathrm{g} / \mathrm{mile}$ )

CO emissions, \% of ULEV

NMHC emissions, \% of ULEV

$\mathrm{NO}_{\mathrm{z}}$ emissions, \% of ULEV

NMHC emissions, \% of EZEV

$\mathrm{NO}_{x}$ emissions, \% of EZEV
23.1

39.2

95.3

38.2

38.5

84.6

4570

4570

289

55

$102(26.5)$

1264

229

729

$25.4(59.6) \quad 26.7(62.8)$

$31.2(73.5) \quad 32.4(76.3)$

$27.7(65.2) \quad 29.0(68.1)$

$0.084(0.135) 0.61(0.98)$

$0.004(0.007) 0.106(0.172)$

$0.008(0.013) 0.46(0.73)$

7.9

57.6

17.5

6.8

175

430

365

68 


\section{FIGURE CAPTIONS}

1) Engine friction as a function of engine speed as obtained from Barnes-Moss, ${ }^{19}$ and Patton et al. ${ }^{20}$ The figure also includes a curve with $65 \%$ of the friction predicted by Barnes-Moss' correlation.

2) Stroke, bore and engine speed for a $15 \mathrm{~m} / \mathrm{s}$ mean piston speed, as a function of engine displacement, for an engine with 2 cylinders and a 0.833 bore to stroke ratio.

3) Generator performance map for the stoichiometric vehicle. The points indicate the conditions at which the engine-generator operates for low power and high power conditions.

4) Generator performance map for the lean burn vehicle. The points indicate the conditions at which the engine-generator operates for low power and high power conditions.

5) Contour plots of combined cycle fuel economy as a function of engine speed and displacement for the stoichiometric car. The figure shows a point representing the optimum engine operating conditions. All the points in these graphs meet the minimum acceleration requirement of $10 \mathrm{~s}$ for $0-97 \mathrm{~km} / \mathrm{h}$.

6) Contour plots of combined cycle fuel economy as a function of engine speed and displacement for the lean-burn car. The figure shows a point representing the optimum engine operating conditions. All the points in these graphs meet the minimum acceleration requirement of $10 \mathrm{~s}$ for $0-97 \mathrm{~km} / \mathrm{h}$.

7) Contour plots of continuous hill climbing slope at $97 \mathrm{~km} / \mathrm{h}$ as a function of engine displacement and speed at the low power conditions for the stoichiometric car. The figure shows a point representing the optimum engine operating conditions. All the points in these graphs meet the minimum acceleration requirement of $10 \mathrm{~s}$ for $0-97$ $\mathrm{km} / \mathrm{h}$.

8) Contour plots of continuous hill climbing slope at $97 \mathrm{~km} / \mathrm{h}$ as a function of engine displacement and speed at the low power conditions for the lean-burn car. The figure shows a point representing the optimum engine operating conditions. All the points in these graphs meet the minimum acceleration requirement of $10 \mathrm{~s}$ for $0-97 \mathrm{~km} / \mathrm{h}$. 


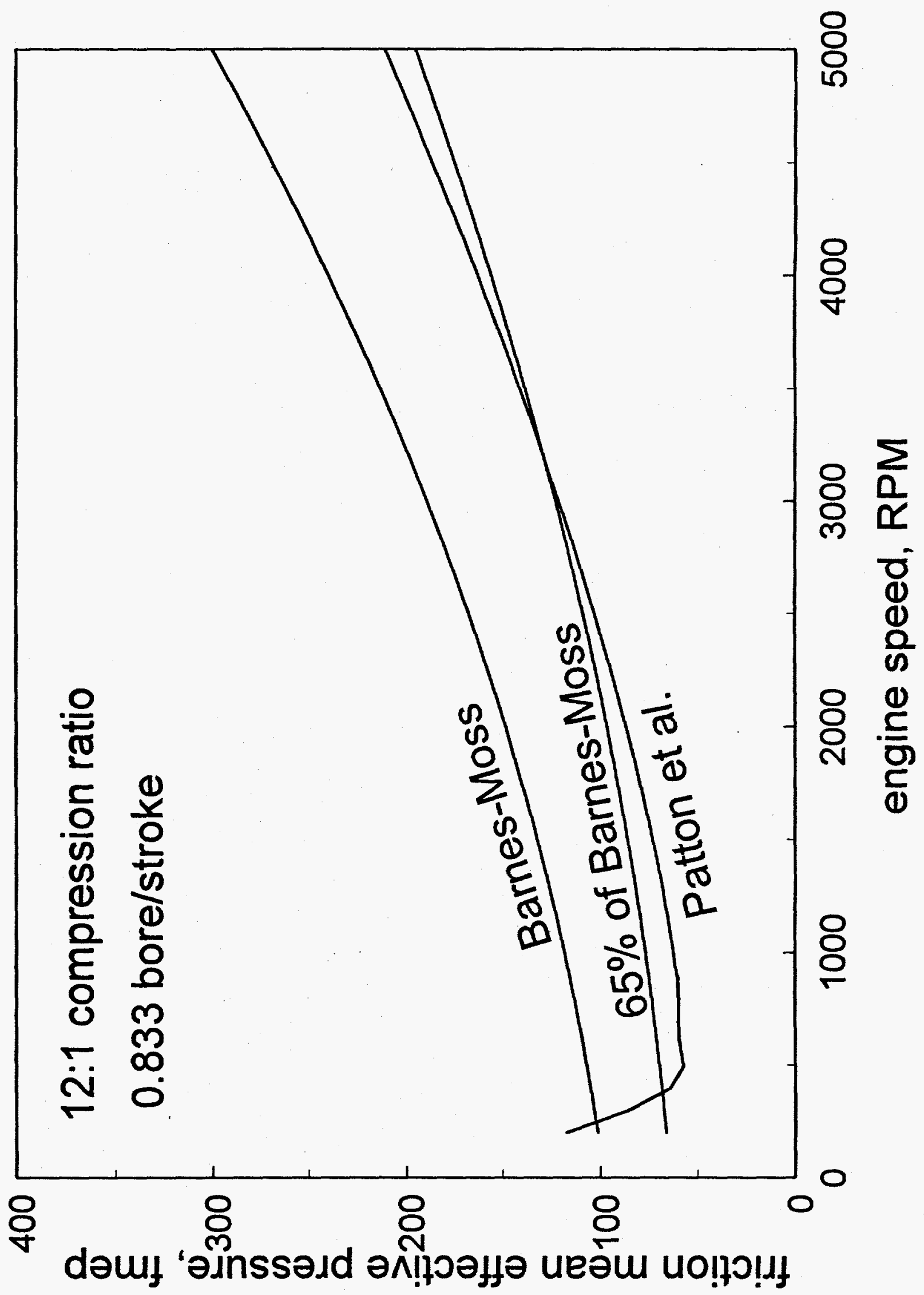

Figure 1 


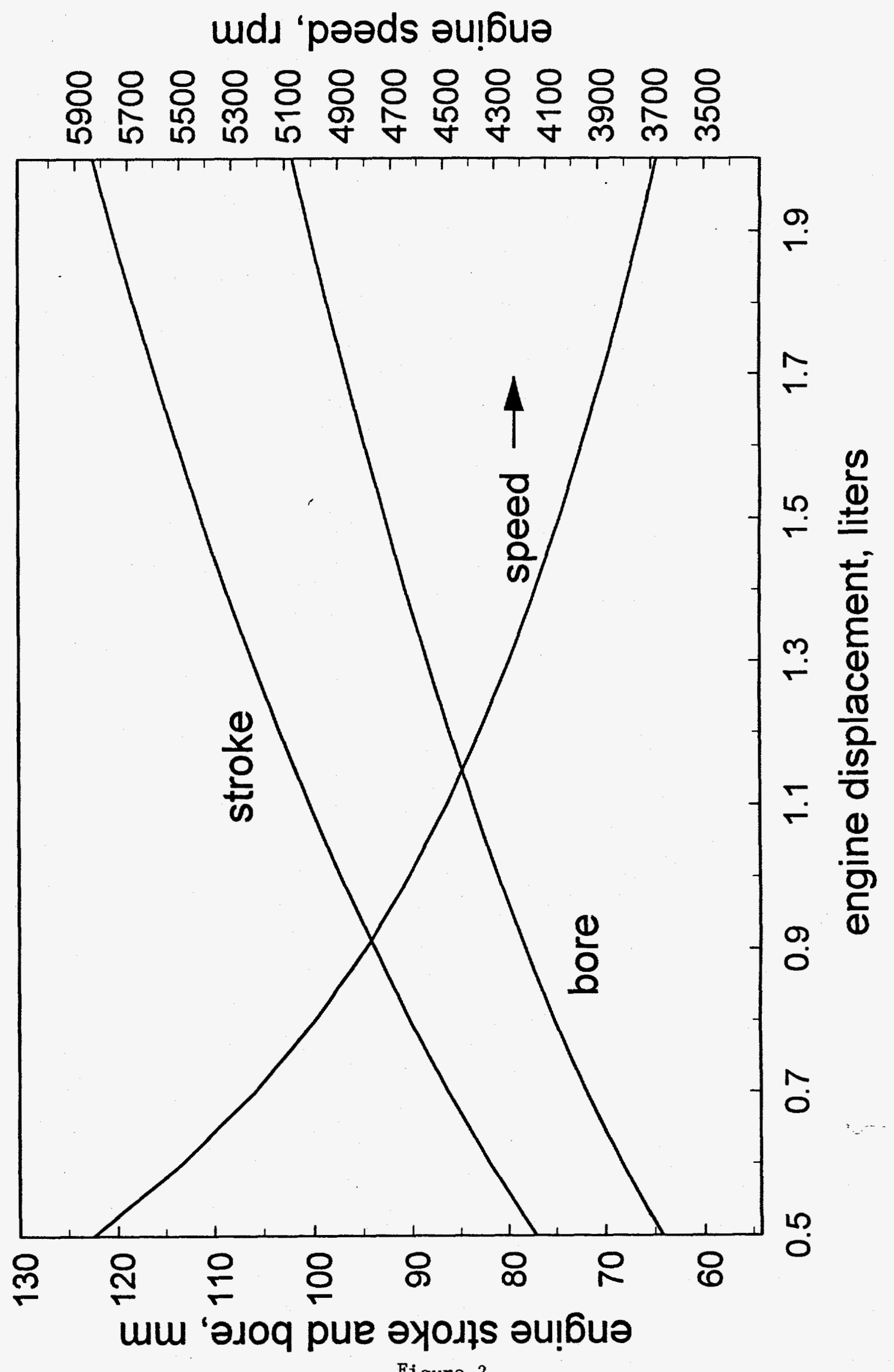

Figure 2 


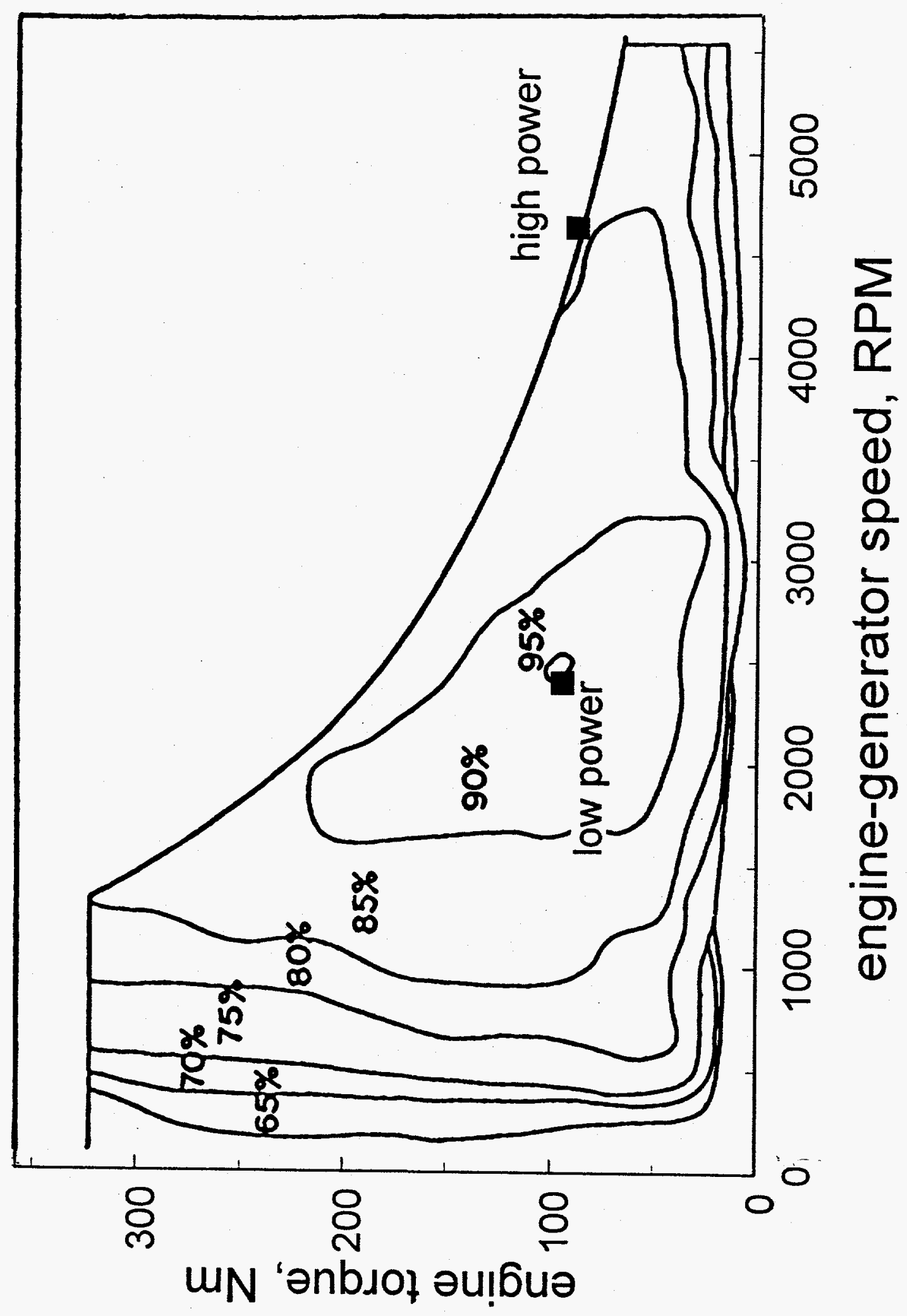

Figure 3 


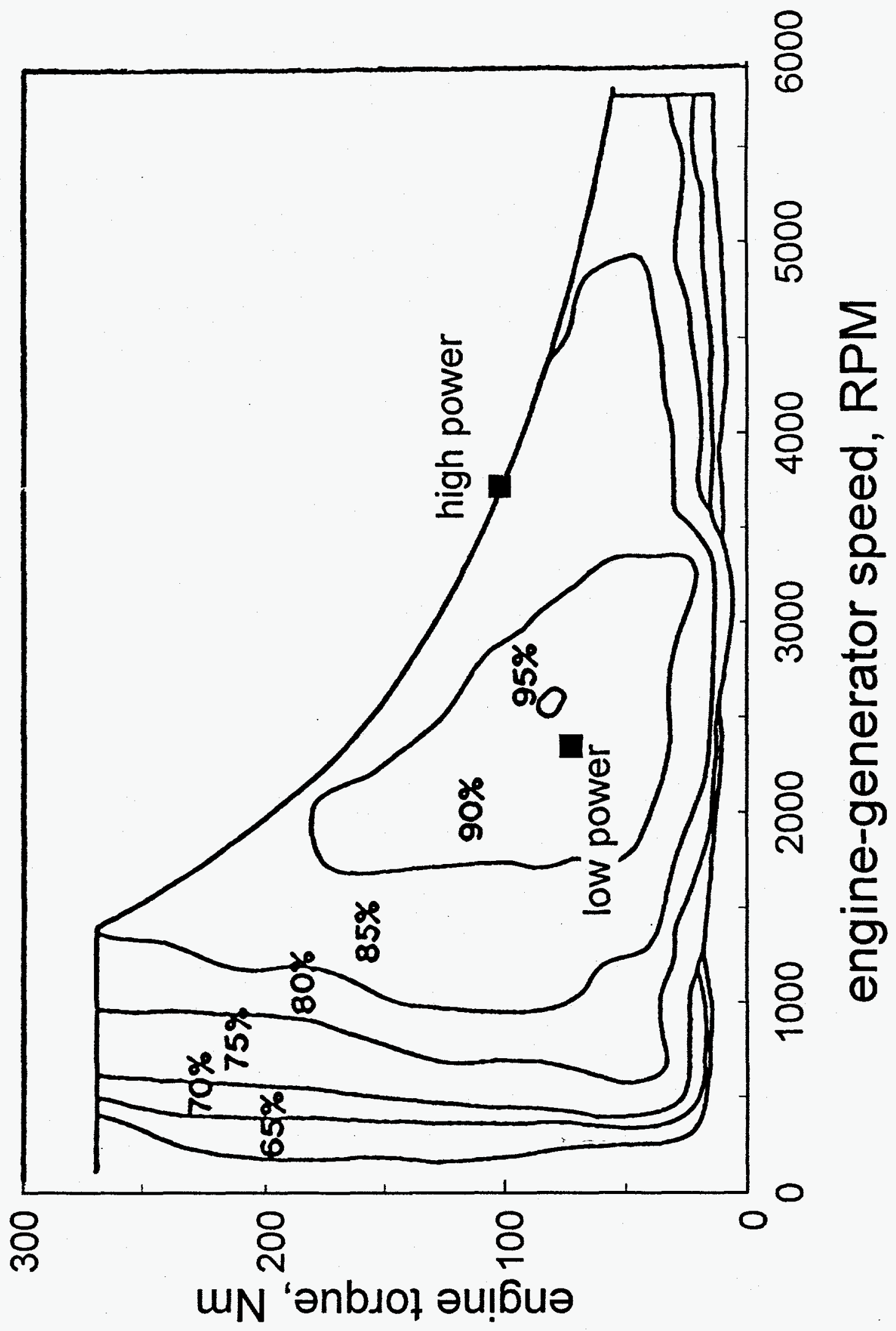

Figure 4 


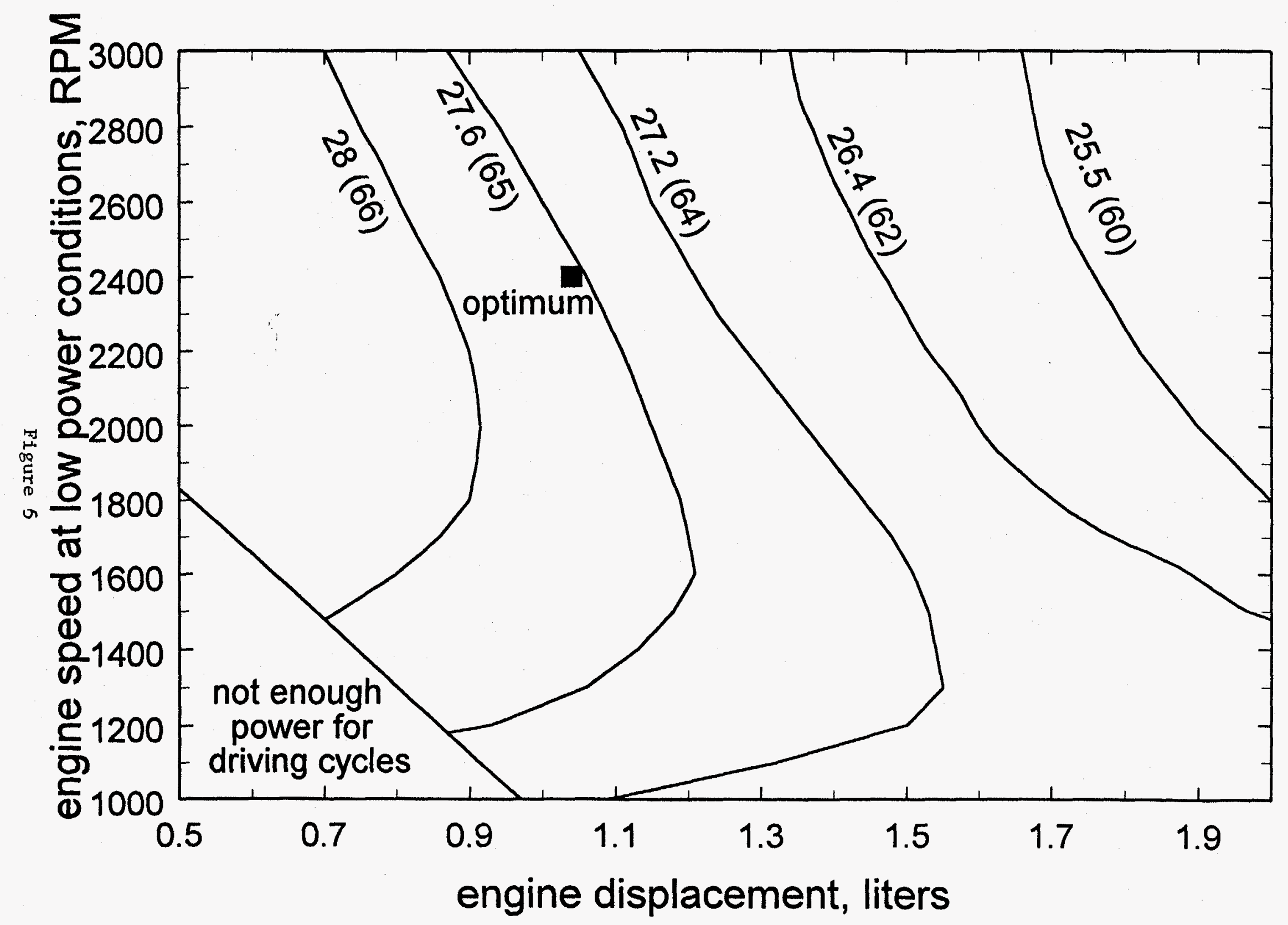




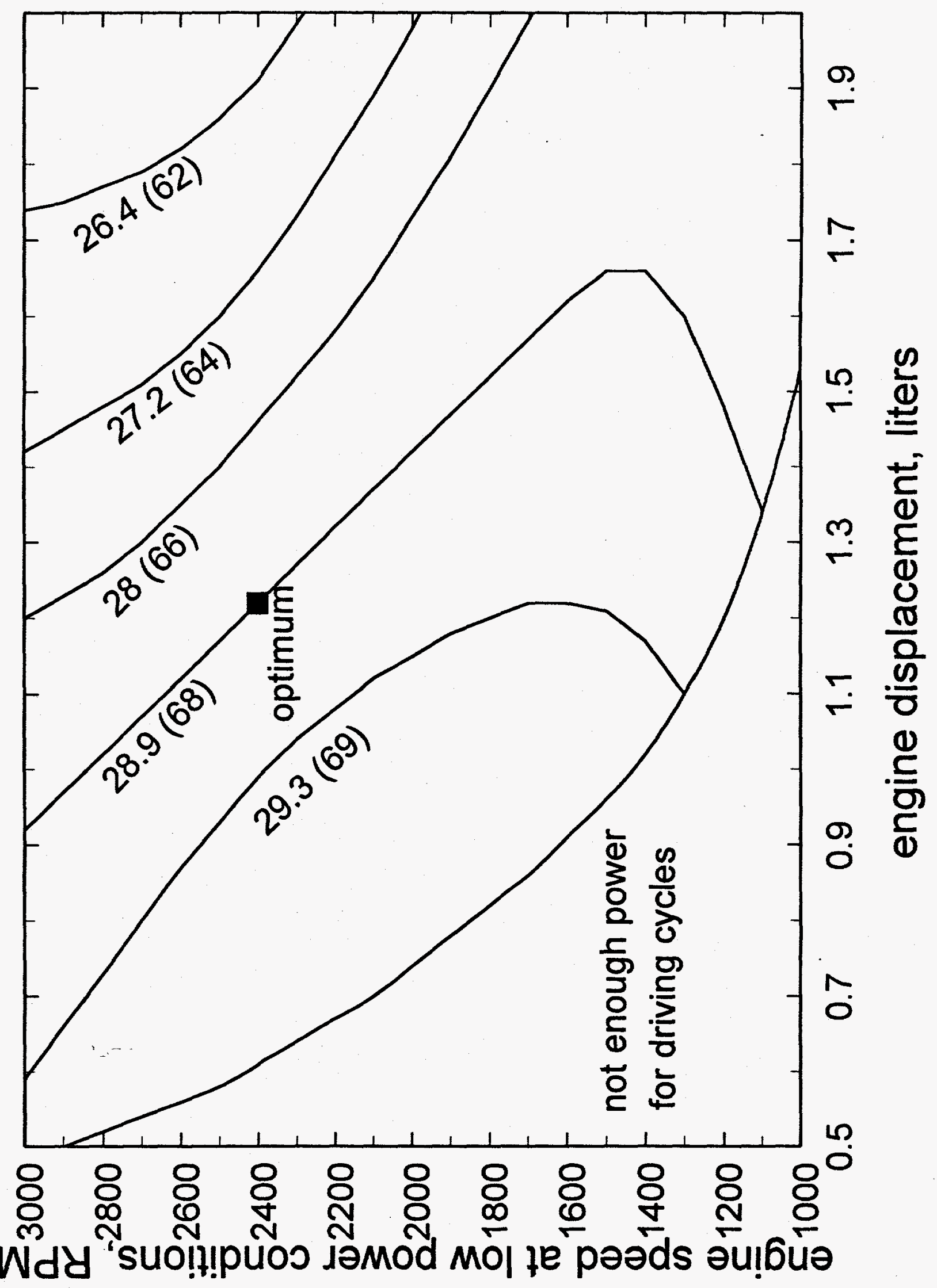

Figure 6 


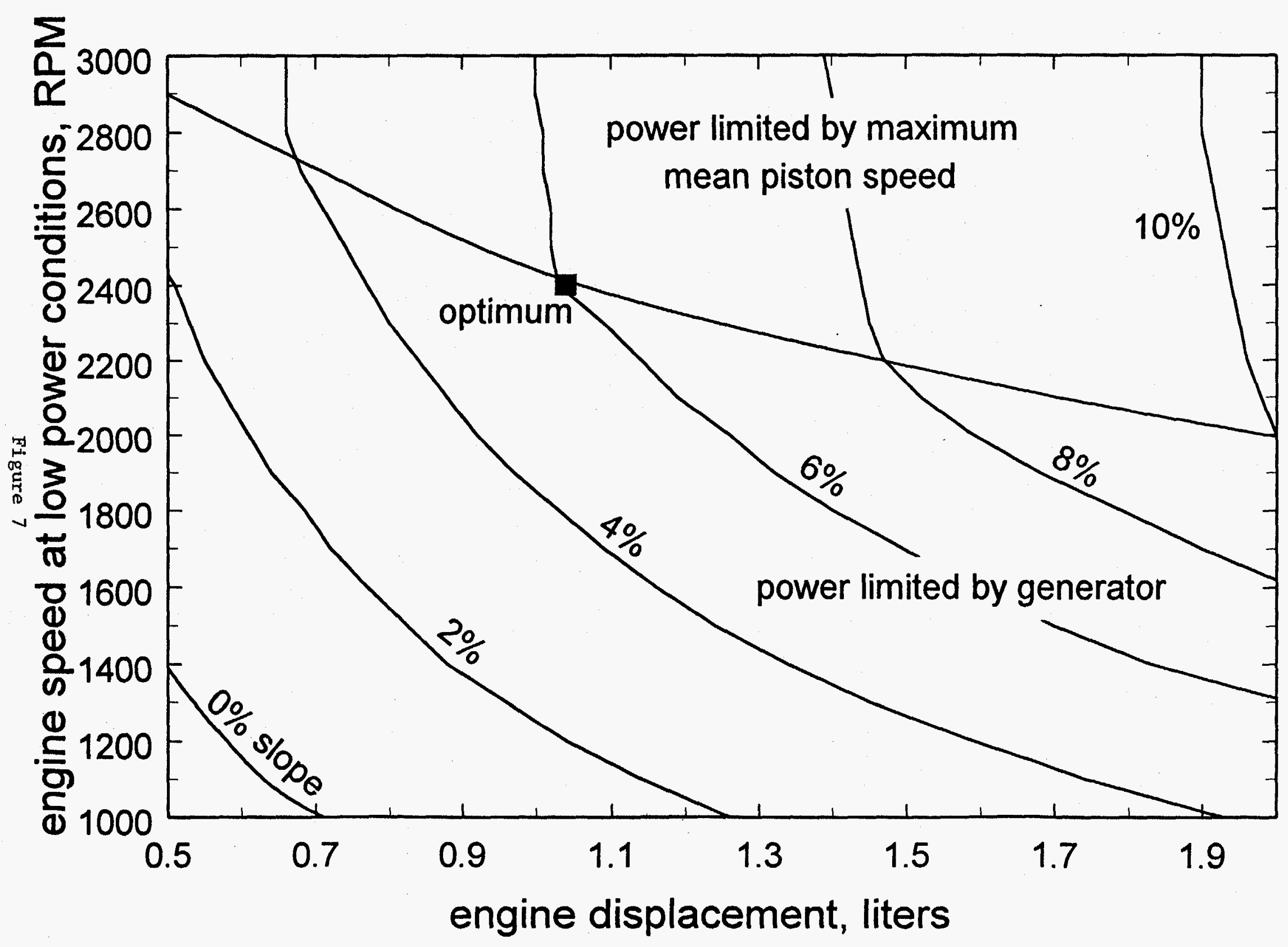




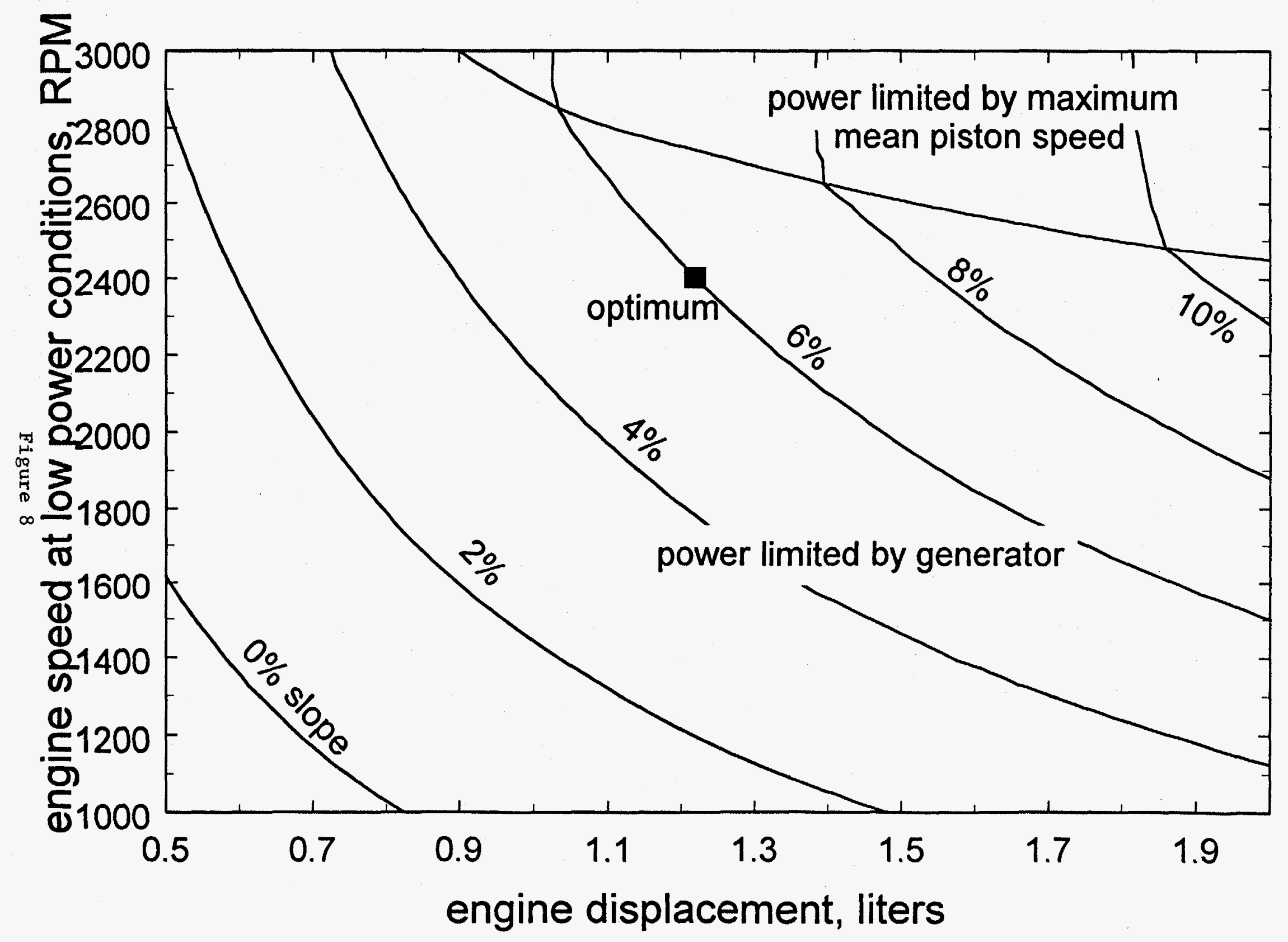

